\title{
Prognostic potential of positron emis- sion tomography (PET) prior and after au- tologous stem cell transplant (ASCT) for chemoresistant Hodgkin lymphoma
}

Vsevolod G. Potapenko', 2, Natalia B. Mikhaylova1, Irina A. Skorokhod ${ }^{2}$, Daria A. Chaginskaya ${ }^{2}$, Victoria V. Ryabchikova $^{2}$, Eleonora I. Podoltseva ${ }^{2}$, Victor V. Ipatov ${ }^{3}$, Igor V. Boykov ${ }^{3}$, Vyacheslav N. Semelev ${ }^{3}$, Dmitriy A. Gornostaev ${ }^{3}$, Nadezhda V. Medvedeva ${ }^{2}$, Boris V. Afanasyev ${ }^{1}$

${ }^{1}$ First St.Petersburg I.Pavlov State Medical University, St.Petersburg, Russia ${ }^{2}$ Haematology Department, City Clinical Hospital №31, St.Petersburg, Russia ${ }^{3}$ S.M.Kirov Military Medical Academy, St.Petersburg, Russia

Contact: Dr. Vsevolod G.Potapenko, City Clinical Hospital №31, St.Petersburg, Russia E-mail: potapenko.vsevolod@mail.ru

\section{Aim of the study}

To evaluate prognostic significance of pre- and post-transplant PET-scans in patients with relapsed or refractory Hodgkin disease.

\section{Patients and methods}

The retrospective data on 84 consecutive patients receiving high dose chemotherapy with ASCT were analyzed. Their median age was 26.6 (10-62) years. Median follow-up was 25 (1-85) months. Conditioning regimens were as follows: BEAM $(n=48)$, BEAM with bendamustine $(n=32), C B V$ $(\mathrm{n}=4)$. Pre-transplant PET scanning (PET1) was performed in 83 pts. In 57 cases, repeated PET scans have been carried out (PET2). Survival was estimated using Kaplan-Meier method.

\section{Results}

Two-year overall and event-free survival rates were $70.6 \%$ and $58.7 \%$ respectively. Patients with CT-confirmed progres- sion prior to ASCT had a worse prognosis. Predictive value of PET-status was shown in chemosensitive patients (partial/ complete response by CT-scan). The overall and event-free survival rates in PET1-negative and PET1-positive patients were $82 \%$ vs $62 \%(p=0.056)$ and $74 \%$ vs $44 \%(p=0.003)$, respectively. In PET2-negative and PET2-positive patients, overall and event-free survival were $90 \%$ vs $65 \%(\mathrm{p}=0.013)$, and $72 \%$ vs $52 \%(\mathrm{p}=0.014)$, respectively. Event-free and overall survival for PET1+PET2- group didn't differ significantly from appropriate level in PET1- patients. Prognostic significance of PET2 was superior to predictive value of PET1 results. Conclusion

CT-chemosensitivity exceeds PET in the prognostic significance. Patients with CT-proven response may benefit from PET scanning. While overall prognosis of PET-positive patients is worse, an additional post-transplant PET may be performed for further risk stratification. The PET1+PET2+ group is at higher risk, with regard of probable relapse.

\section{Keywords}

Positron emission tomography (PET), Hodgkin lymhoma, autologous stem cell transplantation (ASCT). 


\section{Роль позитронно-эмиссионной томографии (ПЭТ) до и после аутологичной трансплантации стволовых клеток крови (АТСКК) по поводу химиорезистентной лимфомы Ходжкина}

Всеволод Г. Потапенко ${ }^{1,2}$, Наталья Б. Михайлова ${ }^{1}$, Ирина А. Скороход $^{2}$, Дарья А. Чагинская ${ }^{2}$, Виктория В. Рябчикова $^{2}$, Элеонора И. Подольцева ${ }^{2}$, Виктор В. Ипатов ${ }^{3}$, Игорь В. Бойков ${ }^{3}$, Вячеслав Н. Семелев ${ }^{3}$, Дмитрий А. Горностаев ${ }^{3}$, Надежда В. Медведева ${ }^{2}$, Борис В. Афанасьев ${ }^{1}$

\footnotetext{
${ }^{1}$ Первый Санкт-Петербургский государственный университет им И.П. Павлова, Санкт-Петербург, Россия ${ }^{2}$ Городской гематологический центр, Городская клиническая больница №31, Санкт-Петербург, Россия ${ }^{3}$ Военно-медицинская академия им С.М. Кирова, Санкт-Петербург, Россия
}

\section{Цель работы}

Сравнение прогностической ценности ПЭТ-статуса до и после аутологичной трансплантации у пациентов с рецидивной или химиорезистентной лимфомой Ходжкина.

\section{Материалы и методы}

Проанализированы данные 84 пациентов, получавших лечение в период с 10.2007 по 11.2015 г.г. Медиана возраста 26.6 года (10-62). Медиана наблюдения 25 месяцев (1-81). Режимы кондиционирования: «ВЕАМ» $(\mathrm{n}=48)$, «BЕАМ с бендамустином» $(\mathrm{n}=32)$, «СBV» $(\mathrm{n}=4)$. ПЭТ-исследование выполнено до АТСКК у 83 пациентов (ПЭТ1), после - у 57 пациентов (ПЭТ2). Выживаемость оценивалась по методу Каплана-Мейера.

\section{Результаты}

Общая двухлетняя (OB) и бессобытийная выживаемость (БСВ) составила 70,6\% и 58,7\%. Худший прогноз оказался у пациентов с прогрессированием лимфомы по данным компьютерной томографии (КТ) на момент начала кондиционирования. При наличии КТ-ответа
ПЭТ-статус лимфомы показал прогностическое значение. Двухлетняя ОВ пациентов с ПЭТ1-негативным и ПЭТ1-позитивным статусом составила $82 \%$ и $62 \%$ $(\mathrm{p}=0,056)$, а БСВ $74 \%$ и $44 \%(\mathrm{p}=0,003)$. Двухлетняя ОВ у пациентов с ПЭТ2-позитивным и ПЭТ2-негативным статусом составила $65 \%$ и $90 \%(\mathrm{p}=0,013)$. БСВ в группах ПЭТ2-позитивным и ПЭТ2-негативным была 52\% и 72\% $(\mathrm{p}=0,014)$. Прогностическое значение ПЭТ2 значительно превышает значение ПЭТ1, при этом ОВ и БСВ в группах ПЭТ1+ПЭТ2- и ПЭТ1- не отличалась.

\section{Выводы}

Химиочувствительность опухоли, оцененная с помощью КТ, является наиболее важным фактором прогноза. ПЭТ-позитивность перед АТСКК и, в особенности, после нее является неблагоприятным фактором. При этом ПЭТ после завершения терапии позволяет выделить пациентов с наихудшим прогнозом (ПЭТ1+ПЭТ2+), нуждающихся в дальнейшем лечении.

\section{Ключевые слова}

Позитронно-эмиссионная томография (ПЭТ), лимфома Ходжкина, аутологичная трансплантация стволовых клеток (АТСКК). 